\title{
Comportamento da corrosão microbiológica do aço duplex com aplicação de sais de quaternário de amônio
}

\author{
Microbiological corrosion behavior of the duplex \\ steel with the ammonium quaternary \\ salts application
}

\author{
Lindomar Cordeiro Antunes de Araújo ${ }^{1}$, Paulo Roberto da Silva Ribeiro ${ }^{1}$, \\ Leila Yone Reznik ${ }^{2}$, Márcia Teresa Soares Lutterbach ${ }^{3}$, \\ Eliana Flávia Camporese Sérvulo ${ }^{2}$
}

\footnotetext{
${ }^{1}$ Universidade Federal do Maranhão, Centro de Ciências Sociais, Saúde e Tecnologia, Núcleo de Pesquisas em Ciências Farmacêuticas e Química Analítica Aplicada (NUPFARQ), CEP: 65900000, Imperatriz, Maranhão, Brasil.

${ }^{2}$ Universidade Federal do Rio de Janeiro, Centro de Tecnologia, Escola de Química, Laboratório de Biossíntese, Biocorrosão e Biodegradação, CEP: 21941-909, Rio de Janeiro, Rio de Janeiro, Brasil.

${ }^{3}$ Instituto Nacional de Tecnologia - Laboratório de Biocorrosão e Biodegradação (LABIO), CEP: 20081310, Rio de Janeiro, Rio de Janeiro, Brasil.

e-mail: lindomarc@eq.ufrj.br,pauloufv@hotmail.com,lreznik@eq.ufrj.br, eliana@eq.ufrj.br, mar-

cia.lutterbach@int.gov.br
}

\begin{abstract}
RESUMO
A corrosão microbiológica tem causado diversos prejuízos para variados segmentos industriais que utilizam os materiais metálicos em seus sistemas. Uma forma de minimizar e até mesmo controlar os problemas causados pela corrosão microbiológica tem sido a aplicação de biocidas nestes sistemas. Neste trabalho, a corrosão microbiológica do aço duplex UNS S 31803 foi avaliada com a aplicação de um biocida contendo sais de quaternário de amônio em água de produção de petróleo de uma plataforma offshore, simulando ambiente hipersalino. A fim de avaliar a corrosão microbiológica com a aplicação do biocida foram utilizadas técnicas microbiológicas como número mais provável - NMP - e eletroquímicas (medidas de potencial a circuito aberto e polarização). O biocida impactou os grupos bacterianos, eliminando inclusive dois grupos bacterianos (bactérias produtoras de ácido aeróbias e redutoras de sulfato) na fase séssil. Os potenciais medidos a circuito aberto mais elevados foram observados quando o biocida contendo sais de quaternário de amônio foi aplicado nos sistemas. Os valores potenciais de pite obtidos pelas análises de polarização mostraram que os microrganismos influenciaram nos valores e que o biocida manteve os potenciais em torno de $1000 \mathrm{mV}_{\text {ECS. }}$. Os ensaios de polarização permitiram analisar através de instabilidades nas curvas e variações nas densidades de corrente passiva ao longo do tempo, a complexa dinâmica ocorrente sobre a superfície metálica devido à competição entre formação e desestabilização de película passiva, adsorção e dessorção de biocida/biofilme.
\end{abstract}

Palavras-chave: Aço duplex, corrosão microbiológica, sais de quaternário de amônia.

\begin{abstract}
Microbiological corrosion has caused several damages to several industrial segments that use the metallic materials in their systems. One way of minimizing and even controlling this problem has been the biocide application in these systems. In this work, the microbiological corrosion of the UNS S 31803 duplex steel was evaluated by the application of a biocide containing quaternary ammonium salts in petroleum production water from an offshore platform, simulating the hypersaline environment. In order to evaluate the microbiological corrosion, microbiological technique as Most Probable Number method (MPN) and electrochemical technique (open circuit potential and polarization measures) were used. The biocide impacted on the present microbiota, eliminating two bacterial groups (aerobic and sulfate reducing bacteria) in the sessile phase. The highest open circuit measured potentials were observed when the biocide containing quaternary ammonium salts was applied to the systems. The potential pite values obtained by the polarization analyzes showed that the microorganisms influenced the values and that the biocide kept the potentials around $1000 \mathrm{mV}_{\mathrm{ECS}}$. The
\end{abstract}


polarization tests allowed to analyze, through instability in the curves and variations in passive current densities over time, the complex dynamics occurring on the metal surface due to competition between formation and destabilization of passive film, adsorption and desorption of biocide/biofilm.

Keywords: Duplex steel, microbiological corrosion, quaternary ammonium salts.

\section{INTRODUÇÃO}

Diversos segmentos industriais utilizam as ligas metálicas em seus sistemas de operação. Dentre esses segmentos podemos citar as indústrias do petróleo, petroquímica, naval e outras. Com o passar do tempo, os sistemas destes ramos industriais vêm apresentado problemas e ocasionando prejuízos. Isso ocorre pelo fato de que os metais podem sofrer degradação com o tempo e a depender de onde são utilizados, a sua vida útil pode ser afetada. Por isso, enfoca-se a importância de conhecer o ambiente onde estes materiais serão utilizados, bem como a adoção de formas de preservação a sua degradação para que se possa utilizá-los o maior tempo possível com segurança.

Independente do meio de onde serão utilizados, os materiais metálicos devem apresentar propriedades de resistência as adversidades do ambiente, ou, pelo menos se fazer uso de métodos que os proteja contra, por exemplo, íons ou substâncias agressivas (íon cloreto, ácido sulfídrico, por exemplo). Os processos de deterioração dos materiais metálicos, conhecido como corrosão, podem ocorrer via mecanismos químico ou eletroquímico e podem ser associados ou não a esforços mecânicos [1]. O mecanismo de corrosão pode ser ainda mais intensificado quando os microrganismos estão presentes (corrosão microbiológica) face a ação do metabolismo realizado na superfície do material, como por exemplo, produção de material polimérico extracelular, redução de íons sulfato a sulfito, variação do $\mathrm{pH}$ (em áreas localizadas) dentre outros [2][3].

A ocorrência da corrosão microbiológica está atrelada a formação de biofilme. Os biofilmes são constituídos por uma comunidade de microrganismos inserida em uma matriz conhecida de material polimérico extracelular (MPE) associada a uma superfície. Apesar dos biofilmes serem prejudiciais as superfícies metálicas, eles são benéficos as células microbianas. Isto é decorrente devido o MPE atuar como barreira de proteção a ação de agente químicos (biocidas, por exemplo) que sejam prejudiciais ao desenvolvimento microbiano [2][3][4][5].

Face a isso, a utilização de materiais que sejam resistentes as adversidades do ambiente e ao ataque microbiano deve ser priorizado, levando em conta os custos a longo prazo. Uma alternativa de material é o aço inoxidável duplex. Este aço vem sendo bastante utilizado por ser resistente a corrosão em virtude de sua propriedade em formar película protetora, conhecida como camada passiva, em sua superfície [6][7]. Este material possui essa capacidade por possuir uma elevada concentração de cromo em sua composição química.

No entanto, apesar de ser resistente a corrosão os aços duplex não estão imunes a esta, principalmente quando o íon cloreto e os microrganismos estão presentes no ambiente [2][8]. O ataque de íons agressivos concomitantemente a ação microbiana pode levar a ruptura da camada passiva. E isso afeta diretamente a sua resistência no ambiente onde são utilizados levando a formação de pite (corrosão localizada).

Para que se possa evitar, e até mesmo minimizar os efeitos de íons agressivos e a ação dos microrganismos, existem técnicas para monitoramento e controle da corrosão, mesmo mediada por microrganismos.

No caso da corrosão microbiológica, uma técnica que vem sendo bastante utilizada é aplicação de biocidas, por ser simples e de fácil aplicação.

Salienta-se, no entanto que o biocida a ser utilizado seja compatível com o sistema a ser aplicado, tomando-se o cuidado de estabelecer o modo de aplicação, no tempo de contato e na concentração a ser utilizada. O tempo de contato do biocida deve ser previamente definido, pois muitos microrganismos são eliminados imediatamente, enquanto outros levam maior tempo ou não são eliminados. Se a concentração e o tempo de contato não forem usados adequadamente isso pode inclusive levar a uma resistência microbiana, o que dificultará ainda mais o controle da corrosão microbiológica [9][10].

Face ao exposto, o presente trabalho teve como objetivo avaliar a corrosão microbiológica do aço duplex UNS S 31803 em água de produção de petróleo com elevada salinidade com aplicação de um biocida contendo sais de quaternário de amônio. 


\section{MATERIAIS E MÉTODOS}

\subsection{Cupons metálicos e biocida}

Neste trabalho foram usados corpos de prova (CPs) de aço duplex (UNS S 31803) retangulares com diferentes dimensões. Para as análises microbiológicas as dimensões dos CPs foram de $4,0 \mathrm{~cm}$ x $1,0 \mathrm{~cm} \mathrm{x} 0,3 \mathrm{~cm}$ e furo de $0,2 \mathrm{~cm}$ de diâmetro. Para análises eletroquímicas foram utilizados CPs com dimensões de 2,0 cm $\mathrm{x}$ $1,0 \mathrm{~cm}$ x $0,3 \mathrm{~cm}$, conectados a um fio de cobre de modo a permitir contato elétrico, embutidos em resina epóxi, deixando somente uma superfície exposta. Imediatamente antes do uso, os CPs foram polidos (com lixas de granulometrias 120 e 600), lavados com água destilada, rinsados com álcool etílico e secos em jato de ar quente. Já o biocida utilizado consistiu em um blend formado por uma combinação de sais de quaternário de amônio - Quats.

\subsection{Microrganismos}

Para obtenção de culturas microbianas reconhecidamente envolvidas na deterioração de materiais, água oriunda de um oleoduto foi cultivada em diferentes meios de cultura, conforme descrito a seguir:

- Bactérias heterotróficas aeróbias (BHA) em caldo nutriente (g/L): Peptona de carne 5,0; Extrato de levedura 3,0 ; Dextrose 9,0 e $\mathrm{pH}$ ajustado para $7,0 \pm 2$;

- Bactérias produtoras de ácido aeróbias (BPAA) e bactérias produtoras de ácido anaeróbias (BPAAn) em Caldo vermelho de fenol (g/L): Extrato de peptona 10; extrato de carne 1,0; vermelho de fenol 0,018; Glicose 10 e pH =7,4 \pm 2 . Para BPAAn, a condição de anaerobiose foi garantida através de purga de nitrogênio no meio;

- Bactérias redutora de sulfato (BRS) em meio POSTGATE E (g/L)[11]: $\mathrm{KH}_{2} \mathrm{PO}_{4}$ 0,5; $\mathrm{NH}_{4} \mathrm{Cl} 1,0$; $\mathrm{CaCl}_{2} \cdot 6 \mathrm{H}_{2} \mathrm{O} 1,0 ; \mathrm{MgCl}_{2} .7 \mathrm{H}_{2} \mathrm{O} 2,0 ; \mathrm{FeSO}_{4} \cdot 7 \mathrm{H}_{2} \mathrm{O} 1,0 ; \mathrm{FeSO}_{4} \cdot 7 \mathrm{H}_{2} \mathrm{O}$ 1,0; Extrato de lêvedo 0,1; Ácido ascórbico 0,5; Agar-agar 1,9; Ao meio também foram adicionados $7 \mathrm{~mL}$ de solução de lactato de sódio $50 \% ; 4 \mathrm{~mL}$ de solução de resazurina $0,025 \%(\mathrm{~m} / \mathrm{v})$ e pH ajustado para 7,6 \pm 2 .

Neste caso, a salinidade de todos os meios foi ajustada para $45 \mathrm{~g} \mathrm{NaCl} / \mathrm{L}$ de modo a estabelecer a salinidade da água de origem.

Para a coleta da água foram utilizados dois frascos estéreis de $100 \mathrm{~mL}$, sendo a água neles armazenada e transportada para o laboratório em condição refrigerada (cerca de $10^{\circ} \mathrm{C}$ ), por acondicionamento em sacolas térmicas com sacos de gel refrigerantes reutilizáveis. Em prazo inferior a 24 h, a água foi analisada microbiologicamente. No laboratório, alíquotas de $10 \mathrm{~mL}$ foram cultivadas em três frascos Erlenmeyer de $250 \mathrm{~mL}$ de capacidade contendo $90 \mathrm{~mL}$ de um dos meios de cultura específicos para cultivo das populações bacterianas aeróbias (BHA, BPA), e da mesma forma igual volume de água de oleoduto foi distribuído em três frascos tipo penicilina de $100 \mathrm{~mL}$, cada um contendo $90 \mathrm{~mL}$ de um dos meios próprios para cultivo de BRS e BPAAn.

As culturas microbianas provenientes da água de oleoduto, enriquecidas por uma série de subcultivos em meios específicos conforme descrito, foram aclimatadas por subsequentes cultivos com valores crescentes de $\mathrm{NaCl}$, variando do valor inicial de $45 \mathrm{~g} / \mathrm{L}$ até $220 \mathrm{~g} / \mathrm{L}$. Este procedimento teve como intuito a obtenção de culturas halofílicas de cada população acima referendada para bioaumento da água de produção, cuja salinidade é de $160 \mathrm{~g} \mathrm{NaCl} / \mathrm{L}$.

\subsection{Eletrólito do processo}

Foi utilizado água de produção de uma plataforma offshore contendo $160 \mathrm{~g} / \mathrm{L}$ de salinidade, expressa em $\mathrm{NaCl}$. A Tabela 1 mostra as características físico-química da água utilizada como eletrólito. Para a realização dos ensaios, a água produzida foi suplementada com $(\mathrm{g} / \mathrm{L}): \mathrm{KH}_{2} \mathrm{PO}_{4} 0,5 ; \mathrm{NH}_{4} \mathrm{Cl} 1,0$, extrato de levedura $0,2 \mathrm{e}$ ácidos orgânicos de cadeia curta [ácido lático 60,8; ácido propiônico 50,0 e ácido butírico 44,6], conforme descrito por SOUSA [12] e o pH foi ajustado para 6,0. Também ao eletrólito foi adicionado $\mathrm{Na}_{2} \mathrm{SO}_{4}$ a fim de ajustar a concentração de sulfato àquela do meio Postgate, meio de cultura específico para o cultivo de bactérias redutoras de sulfato (BRS), e, assim, favorecer também a atividade deste grupo microbiano. Considerando que a análise microbiológica da água revelou apenas a presença de BHA, a água foi enriquecida com as culturas halofílicas, de modo a estabelecer concentrações iniciais de $10^{6}$ células $/ \mathrm{mL}$ de cada um dos grupos bacterianos mencionados (item 2.2). 
Tabela 1: Características físico-químicas do eletrólito utilizado nos ensaios

\begin{tabular}{cc}
\hline Análise & Resultados \\
\hline $\mathrm{pH}$ & 5,54 \\
Condutividade elétrica (umho/cm) & 61770,00 \\
$\mathrm{~K}(\mathrm{mg} / \mathrm{L})$ & 75,56 \\
$\mathrm{Na}(\mathrm{mg} / \mathrm{L})$ & 75397,67 \\
$\mathrm{Ca}(\mathrm{mg} / \mathrm{L})$ & 288,66 \\
$\mathrm{Mg}(\mathrm{mg} / \mathrm{L})$ & 36,82 \\
$\mathrm{Fe}(\mathrm{mg} / \mathrm{L})$ & 1,18 \\
$\mathrm{Cu}(\mathrm{mg} / \mathrm{L})$ & 0,24 \\
$\mathrm{Zn}(\mathrm{mg} / \mathrm{L})$ & 0,12 \\
$\mathrm{Mn}(\mathrm{mg} / \mathrm{L})$ & 6,97 \\
$\mathrm{CO}(\mathrm{mg} / \mathrm{L})$ & $<1,00$ \\
$\mathrm{HCO}{ }_{3}^{-}(\mathrm{mg} / \mathrm{L})$ & 90,00 \\
$\mathrm{~S}_{(\mathrm{mg} / \mathrm{L})}$ & 20,10 \\
$\mathrm{Cl}(\mathrm{mg} / \mathrm{L})$ & 90228,68 \\
$\mathrm{~Pb}(\mathrm{mg} / \mathrm{L})$ & $<0,006$ \\
$\mathrm{Cd}(\mathrm{mg} / \mathrm{L})$ & $<0,002$ \\
\hline
\end{tabular}

\subsection{Sistema experimental}

Os experimentos foram conduzidos em cubas de vidro de $1 \mathrm{~L}$ de capacidade, contendo $800 \mathrm{~mL}$ do eletrólito, onde foram dispostos os CPs, fixados à tampa por fios de nylon. O eletrólito foi mantido em constante e suave agitação, por meio de bastão magnético e placa de agitação, o mínimo requerido para manter as células planctônicas em suspensão e, assim, favorecer a colonização das superfícies metálicas. Antes e após cada experimento, a cuba foi desinfetada por imersão em solução de $5 \mathrm{~g} / \mathrm{L}$ de metabissulfito de sódio por 24 horas, sendo a seguir lavada cinco vezes com água destilada estéril, para a total remoção do desinfetante. O sistema foi mantido em sala climatizada, com temperatura variando de 25 a $27^{\circ} \mathrm{C}$. Para os experimentos com o biocida contendo sais de quaternário de amônio (Quats) foi utilizado uma cuba com a respectiva concentração determinada em ensaio preliminar (50 ppm - item 2.5) e realizadas análises microbiológicas (quantificação celular) e/ou eletroquímica.

\subsection{Análises microbiológicas}

Para avaliar o efeito tóxico do biocida (Quat), os diferentes cultivos halofílicos (item 2.2) foram expostos a diferentes concentrações $(25,50,75$ e 100 ppm). Deste modo, foi possível avaliar a ação do Quat sobre culturas mistas halofílicas enriquecidas de BHA, BPAA, BPAAn e BRS na fase planctônica. Também foi realizado um ensaio com adição de água destilada estéril em substituição ao biocida (ensaio controle) para avaliar o crescimento em condições normais.

Para a realização dos ensaios, inicialmente uma amostra do biocida foi convenientemente diluída de modo que a introdução de alíquota de $0,1 \mathrm{~mL}$ da solução estoque no meio permitisse que nele fosse alcançada a concentração desejada de 25, 50, 75 e 100 ppm, conforme indicado por GAYLARDE [13]. A seguir, o meio já com o biocida na concentração desejada foi acrescido de $0,1 \mathrm{~mL}$ dos cultivos microbianos recémpreparados, em separado, cuja concentração no meio reacional foi da ordem $10^{8} \mathrm{NMP} / \mathrm{mL}$.

Os cultivos foram incubados (a temperatura de $\pm 30^{\circ} \mathrm{C}$ ) e observados diariamente quanto ao crescimento: por um período total de 28 dias; sendo BHA (48 horas); BPAA (48 horas); BPAAn (336 horas) e BRS (672 horas). Quando não identificado crescimento microbiano, foi feita a transferência de alíquota de 1 $\mathrm{mL}$ para novo meio $(45 \mathrm{~mL})$ a fim de identificar se o efeito era bacteriostático.

Para determinar as concentrações celulares microbianas, as análises microbiológicas foram realizadas em sistemas contendo microrganismos com e sem aplicação do biocida. As populações de BHA, BPA e BRS, nas fases planctônica e séssil, foram quantificadas pela técnica do Número Mais Provável (NMP) [14] através 
do cultivo, nos respectivos meios apropriados (item 2.2): meio líquido nutriente, meio vermelho de fenol acrescido de $1 \%(\mathrm{~m} / \mathrm{v})$ de glicose, e meio Postgate E modificado [11]. No caso das BPA, os cultivos foram incubados em condição de aerobiose e anaerobiose, para quantificação das BPAA e BPAAn, respectivamente.

\subsection{Análises eletroquímicas}

O potencial de circuito aberto dos corpos de prova foi medido com o auxílio de um multímetro portátil de bancada e eletrodo de referência de calomelano saturado, sendo as medidas feitas em intervalos pequenos nas primeiras 24 horas, e depois a intervalos de 24 horas até integralizar 360 horas. Para cada tempo, o potencial medido representa a média das determinações feitas em dois corpos de prova.

Para cada condição avaliada nos sistemas estudados foram levantadas curvas de polarização anódicas. Os ensaios foram realizados com o auxílio do equipamento AUTOLAB PGSTAT 30, no software NOVA versão 1.11 , com velocidade de varredura $(\mathrm{V} / \mathrm{s})$ de 0,00033 . A célula eletroquímica utilizada para execução deste experimento foi a convencional de três eletrodos. Em todos os ensaios realizados, foram utilizados um eletrodo de trabalho (aço duplex), um contra-eletrodo de platina e um eletrodo de calomelano saturado (ECS) como referência. As curvas de polarização anódicas foram obtidas para corpos de prova imersos no eletrólito (sempre com adição de caldo nutriente em 168 h) nos tempos 0, 24, 168 e 360 horas.

\section{RESULTADOS E DISCUSSÃO}

\subsection{Análise Microbiológica}

Na Tabela 2 são apresentados os resultados do efeito tóxico do biocida de sais de quaternário de amônio (Quat) sobre as populações bacterianas. Nota-se que a partir da concentração de 50 ppm não foi observado crescimento de nenhum grupo bacteriano, sendo detectado efeito bactericida do biocida.

Tabela 2: Efeito tóxico do biocida de sais de quaternário de amônio (Quat) sobre as populações bacterianas.

\begin{tabular}{|c|c|c|c|c|c|c|c|c|}
\hline \multirow{3}{*}{$\begin{array}{c}\text { Biocida } \\
(\mathrm{ppm})\end{array}$} & \multicolumn{8}{|c|}{ Crescimento } \\
\hline & \multicolumn{2}{|c|}{ BHA } & \multicolumn{2}{|c|}{ BPAA } & \multicolumn{2}{|c|}{ BPAAn } & \multicolumn{2}{|c|}{ BRS } \\
\hline & $48 \mathrm{~h}$ & $72 \mathrm{~h}$ & $48 \mathrm{~h}$ & $72 \mathrm{~h}$ & $60 \mathrm{~h}$ & $96 \mathrm{~h}$ & $192 \mathrm{~h}$ & $672 \mathrm{~h}$ \\
\hline 0 & +++ & +++ & +++ & +++ & +++ & +++ & +++ & +++ \\
\hline 25 & ++- & +++ & +-- & +++ & +++ & +++ & ++- & +++ \\
\hline 50 & -- & - - - & - - - & - - - & - - - & - - - & - - - & $\ldots$ \\
\hline 75 & -- & -- & - - - & -- & - & - - - & - - - & -- \\
\hline 100 & - - - & - . - & - - - & - . - & - . - & . . - & - . - & $\ldots$ \\
\hline
\end{tabular}

BHA = bactérias heterotróficas aeróbias; $\mathrm{BPAA}=$ bactérias produtoras de ácido aeróbias; $\mathrm{BPAAn}=$ bactérias produtoras de ácido anaeróbias; BRS = bactérias redutoras de sulfato.

Na literatura há relatos sobre a ação dos Quats sobre os microrganismos, possuindo este biocida amplo espectro de ação. Segundo TORTORA et al. [15], os sais quaternários de amônio são descritos como efetivos contra as bactérias Gram-positivas. No entanto, bactérias Gram-negativas, como por exemplo, algumas espécies presentes no grupo das BHA, como Pseudomonas, dependendo da dose aplicada, são capazes não só de sobreviver na presença dos sais quaternários de amônio, como também de crescer.

Em outro trabalho, CLOETE et al.[16] cita que os sais quaternários de amônio perdem sua eficácia em sistemas contendo altos teores de matéria orgânica ou quando reagem com cátions divalentes. Essas informações são importantes, pois a água empregada neste trabalho, contém diversos cátions (Tabela 1), contendo também material orgânico. Portanto, os constituintes da água também podem interferir no desempenho do biocida em questão. Por isso, a importância de se conhecer a composição do eletrólito a ser utilizado e determinar a menor quantidade do biocida, que além de diminuir gastos, venha afetar o desenvolvimento microbiano nos sistemas onde serão aplicados. Logo, mediante estes resultados (Tabela 2), a concentração de 50 ppm do biocida foi utilizada para a realização dos demais ensaios. 
Na Figura 1 são mostradas as concentrações das células planctônicas expressas em NMP/mL, nos sistemas contendo os corpos de prova (sem e com biocida - Quats) ao longo dos ensaios.
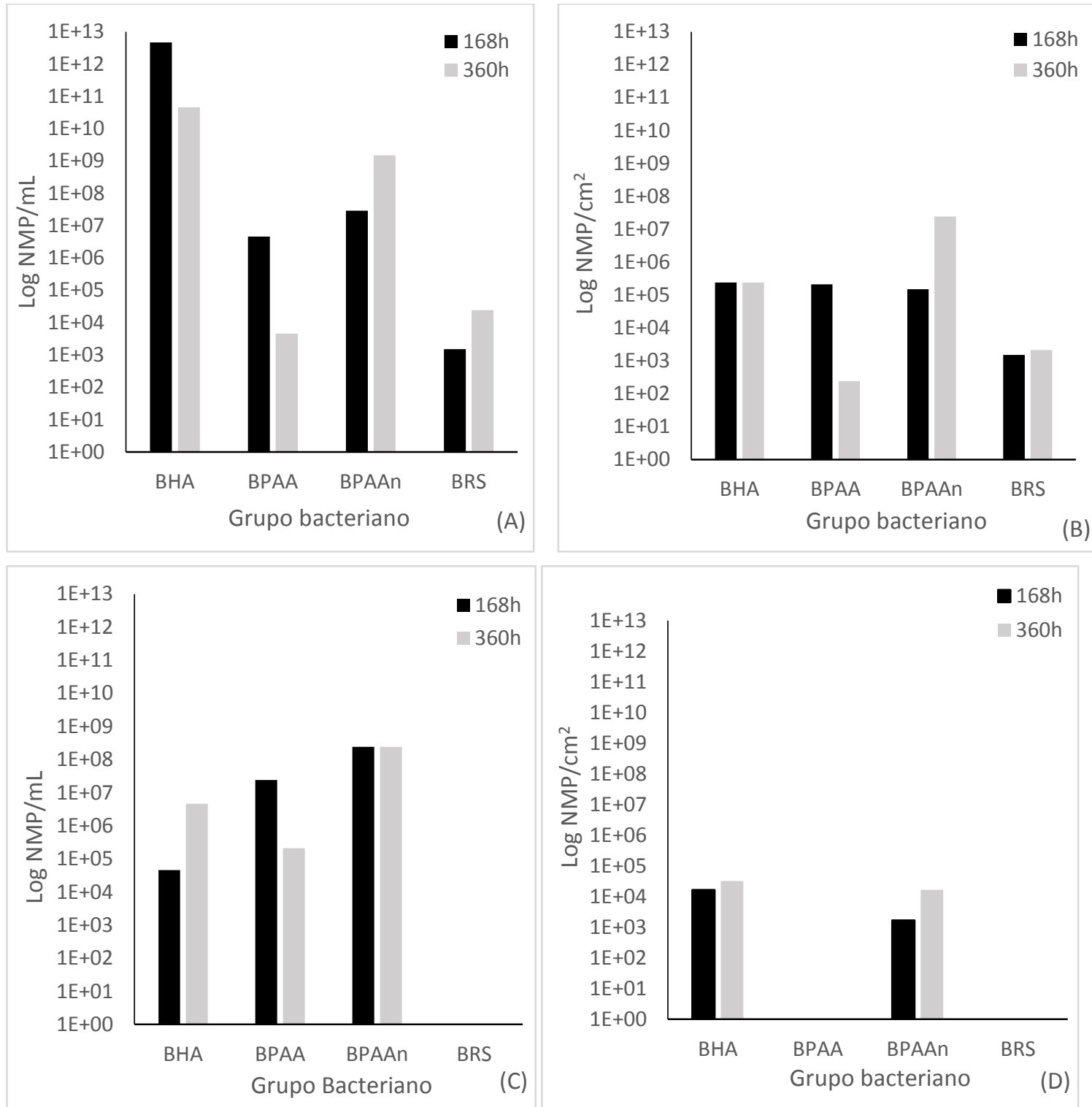

Figura 1: Perfis dos grupos bacterianos na fase planctônica (A, C) e séssil (B, D) em água de produção sem (A, B) e com aplicação de Quats (C, D) na concentração de 50 ppm.

Observando a concentração dos grupos bacterianos presentes na fase planctônica, nota-se que após $168 \mathrm{~h}$ de ensaio todos os grupos que eram foco deste estudo estavam presentes. Na fase planctônica (Figura 1 A), verifica-se que houve aumento (BHA, BPAA e BPAAn) ou diminuição (BRS) dos números dos diferentes grupos bacterianos em relação aos valores iniciais $\left(10^{6} \mathrm{NMP} / \mathrm{mL}\right.$ cada). Nota-se que uma elevada concentração de células metabolicamente ativas foram mantidas na fase planctônica durante o período experimental. Isto demonstra terem sido atendidas as condições nutricionais dos grupos microbianos e/ou podem ser devidas ao desprendimento das células aderidas aos CPs, com o aumento da espessura do biofilme. Ao final dos ensaios $(360 \mathrm{~h}$ ), nota-se na fase planctônica variações das densidades celulares dos grupos bacterianos em relação ao tempo de $168 \mathrm{~h}$. Houve decaimento de 2 e 4 ordens de grandeza para BHA, BPAA e aumento de 2 e 1 ordem de grandeza para BPAAn e BRS, respectivamente. Isto provavelmente ocorreu mediante as atividades metabólicas e consumo do oxigênio no sistema, o que deve ter favorecido o aumento dos grupos bacterianos anaeróbicos (BPAAn e BRS).

No biofilme (Figura $1 \mathrm{~B}$ ), observa-se pela quantificação das populações que todos os grupos bacterianos estavam presentes, inclusive as BRS, as quais se mantiveram em número praticamente constante em or- 
dem de grandeza durante todo o ensaio, provavelmente devido ao metabolismo mais lento e a competição pelas fontes nutricionais. As únicas alterações observadas $(360 \mathrm{~h})$ foram a diminuição de 3 ordens de grandeza para BPAA e aumento de 2 ordens de grandeza para BPAAn. Segundo alguns autores, no biofilme pode ocorrer variações da densidade celular com o tempo. Tal ocorrência é ocasionada mediante interações entre crescimento e morte celular, bem como desprendimento parcial do biofilme em consequência a forças hidrodinâmicas [17][18].

O tratamento com o Quats (Figura C e D) foi capaz de reduzir consideravelmente a colonização microbiana do aço duplex, (Figura 1 A e B ). Verifica-se que inclusive algumas populações que antes estiveram presentes não foram detectadas durante o período experimental, tanto na fase planctônica (BRS) quanto séssil (BPAA e BRS).

A adsorção do Quat em superfície pode alterar as propriedades de adesão de microrganismos em superfícies. Esta alteração pode estar relacionada com o grau de fixação microbiana [19]. Estudos relatam que a composição da membrana externa de células Gram-negativas pode ser modificada após exposição aos compostos quaternários de amônio, o que pode eventualmente aumentar ou diminuir a afinidade de adesão a superfícies [20][21].

Na literatura há relatos da ação de Quats na inativação de biofilmes em superfícies de aço inox. No caso de biofilmes formados com tempo superior a 48 horas, há a necessidade de maior tempo de contato por causa do material polimérico produzido pelos próprios microrganismos que os protegem [22]. Em outros trabalhos, ANDRADE e MACEDO [23] relatam que a ação de Quats contra os microrganismos podem estar relacionada a inibição enzimática, enquanto que DASCHNER [24] relaciona a desnaturação de proteínas da célula.

\subsection{Análise Eletroquímica}

Na Figura 2 são apresentados os resultados de potencial de circuito aberto dos corpos de provas de aço duplex nos experimentos sem e com aplicação do biocida (Quat) na dose de 50 ppm na presença e ausência de microrganismos ao longo de $360 \mathrm{~h}$.

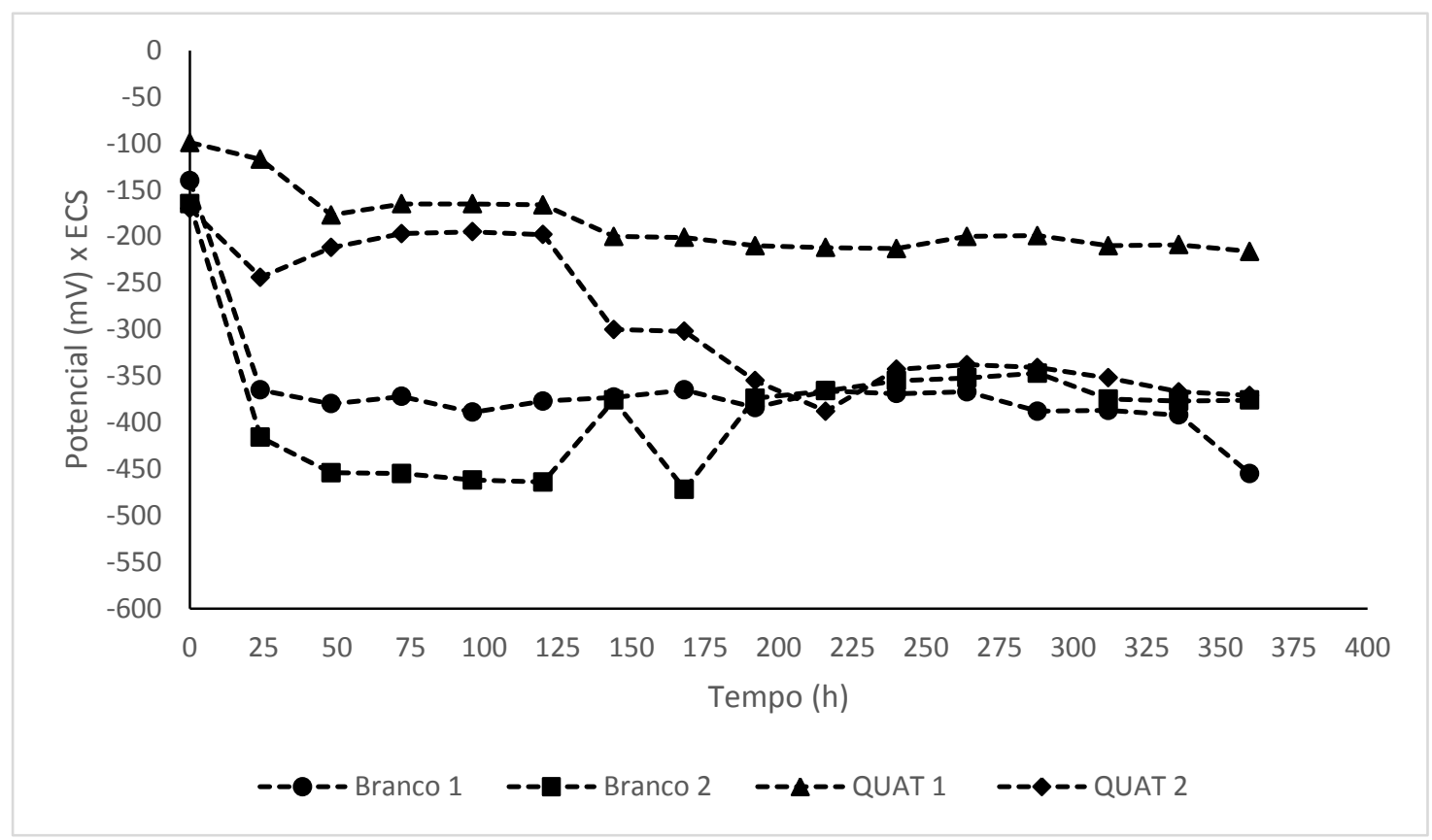

Figura 2: Curvas de potencial de circuito aberto com o tempo obtido para o aço dúplex em água de produção para os diferentes ensaios realizados (Branco $1=$ sem biocida e sem microrganismos; Branco 2 = sem biocida e com microrganismos; Quat1 = com biocida e sem microrganismos; Quat 2 = com biocida e com microrganismos)

Sabe-se que, os aços inoxidáveis, tem como características alta concentração de cromo em sua composição química, o que lhe garante a formação de uma película protetora, conhecida como camada passiva. Nos ensaios realizados com corpos de prova de aço duplex, observou-se queda do potencial nas primeiras $24 \mathrm{~h}$ em 
todas as condições ensaiadas A queda inicial dos potenciais pode estar associada à adsorção e consequente percolação de íons agressivos na camada passiva que está se formando sobre a superfície do metal [25]. No caso do sistema sem microrganismos (branco 1), a curva de potencial tendênciou a uma estabilidade, com algumas variações entre -350 e $-400 \mathrm{mV}_{\mathrm{ECS}}$, apresentando uma queda ao final em $360 \mathrm{~h}$, provavelmente por causa do rompimento da camada passiva.

Na presença dos microrganismos (grupos bacterianos - branco 2), os potenciais mostraram-se em média mais baixos decorrido $24 \mathrm{hs}$ do que no caso do branco 1. Nota-se os valores mais baixos de potencial, principalmente entre 48 e 120 horas de experimento, apresentando após este período uma elevação em torno de 150 horas seguida de queda e novamente elevação com tendência à estabilização a partir de 200 horas. Sabe-se que variações de medidas do potencial, principalmente na presença de microrganismos podem estar atribuídas às características do ambiente (como é o caso da água de produção com alto teor de íon cloreto) e também às atividades bacterianas e subprodutos gerados que afetam o comportamento eletroquímico da superfície dos metais [26].

Em alguns trabalhos na literatura são encontrados poucos casos semelhantes de queda do potencial do aço duplex na presença de microrganismos. ANTONY et al. [27], estudando a corrosão do aço duplex 2205 em meio contendo íons cloreto e BRS, também observaram queda do potencial, que manteve-se estável em torno de $-530 \mathrm{mV}_{\mathrm{ECS}}$ durante todo o ensaio (40 dias). Em outro trabalho, MORADI et al. [28] estudaram o efeito de um microrganismo marinho (Pseudoalteromonas sp.) na microestrutura e corrosão do aço duplex 2205 em água do mar sintética. Estes autores também obtiveram queda do potencial para valores mais ativos (negativos) e aumento na densidade da corrente de corrosão em presença de bactérias. No entanto, não foram encontrados trabalhos onde estudos tenham sido realizados com mais de um grupo bacteriano, o que se torna importante o presente estudo.

No sistema onde os microrganismos estavam ausentes e o biocida foi aplicado (Quat 1), também se observa queda nos valores dos potenciais, no entanto esse decaimento é mais suave, apresentando algumas oscilações ao longo do tempo, com potenciais estabilizando-se em torno de $-200 \mathrm{mV}_{\mathrm{ECS}}$ após $168 \mathrm{~h}$. Em comparação com os demais ensaios realizados, os valores dos potenciais se apresentaram mais elevados.

Com a aplicação do biocida (Quat 2) na presença dos microrganismos é observado comportamento diferente do observado de quando somente o biocida foi aplicado. Nas primeiras 24 h há queda do potencial, havendo em seguida elevação dos valores até 120 h de ensaio. Adiante, nota-se queda dos valores com tendência à estabilização em torno de $-350 \mathrm{mV}_{\mathrm{ECS}}$, a partir de $264 \mathrm{~h}$ até o fim dos experimentos.

Estas variações encontradas nos potenciais dos sistemas com a presença de microrganismos podem estar relacionadas com a formação e desprendimento do biofilme formado, o que expõe novamente a superfície metálica à água de produção e pode provocar um decaimento nos potenciais. Além disso, a literatura mostra que quaternários de amônio apresentam característica surfactante - que até pode inferir certo grau de inibição à corrosão [29][30] - e que, essa característica associada às concentrações aplicadas pode caracterizar uma competição adsorptiva entre microrganismos e a própria molécula deste biocida, levando a instabilidades dos valores de potencial de circuito aberto com o tempo de imersão, principalmente na presença de microrganismos.

Outro fator importante que deve ser levado em consideração na avaliação dos valores de potencial de circuito aberto seria a densidade celular presente no meio. Como observado nas Figuras 1, o biocida contendo Quat impactou de forma significativa os grupos microbianos, sendo que, inclusive, até eliminou alguns grupos (BPAA e BRS) na fase séssil levando a um recobrimento diferenciado da superfície metálica em comparação de quando o somente os microrganismos estavam presentes.

A Figura 3 mostra as curvas de polarização anódica levantadas para estes sistemas (Branco 1, Branco 2, Quat 1 e Quat 2). Os perfis das curvas anódicas para o sistema sem microrganismos e sem biocida (Figura 3A) mostra o aumento de uma resistência à agressividade do meio com a formação de camada passiva e diminuição das densidades de corrente de faixa passiva a partir de 24 horas de imersão dos corpos de prova. Após esse tempo, observa-se um aumento nas densidades de corrente e as curvas mostram faixa passiva de potencial muito similar (em torno de $700 \mathrm{mV}_{\mathrm{ECS}}$ ), apresentando-se praticamente superpostas (168h e $360 \mathrm{~h}$ ). Apesar do aumento das densidades de corrente de $24 \mathrm{~h}$ para 168 e $360 \mathrm{~h}$, os potenciais de pite mantiveram-se para todos os tempos analisados em torno de $1000 \mathrm{mV}_{\mathrm{ECS}}$ o que pode sugerir uma morfologia de filme passivo mais compacta, nesta condição. 


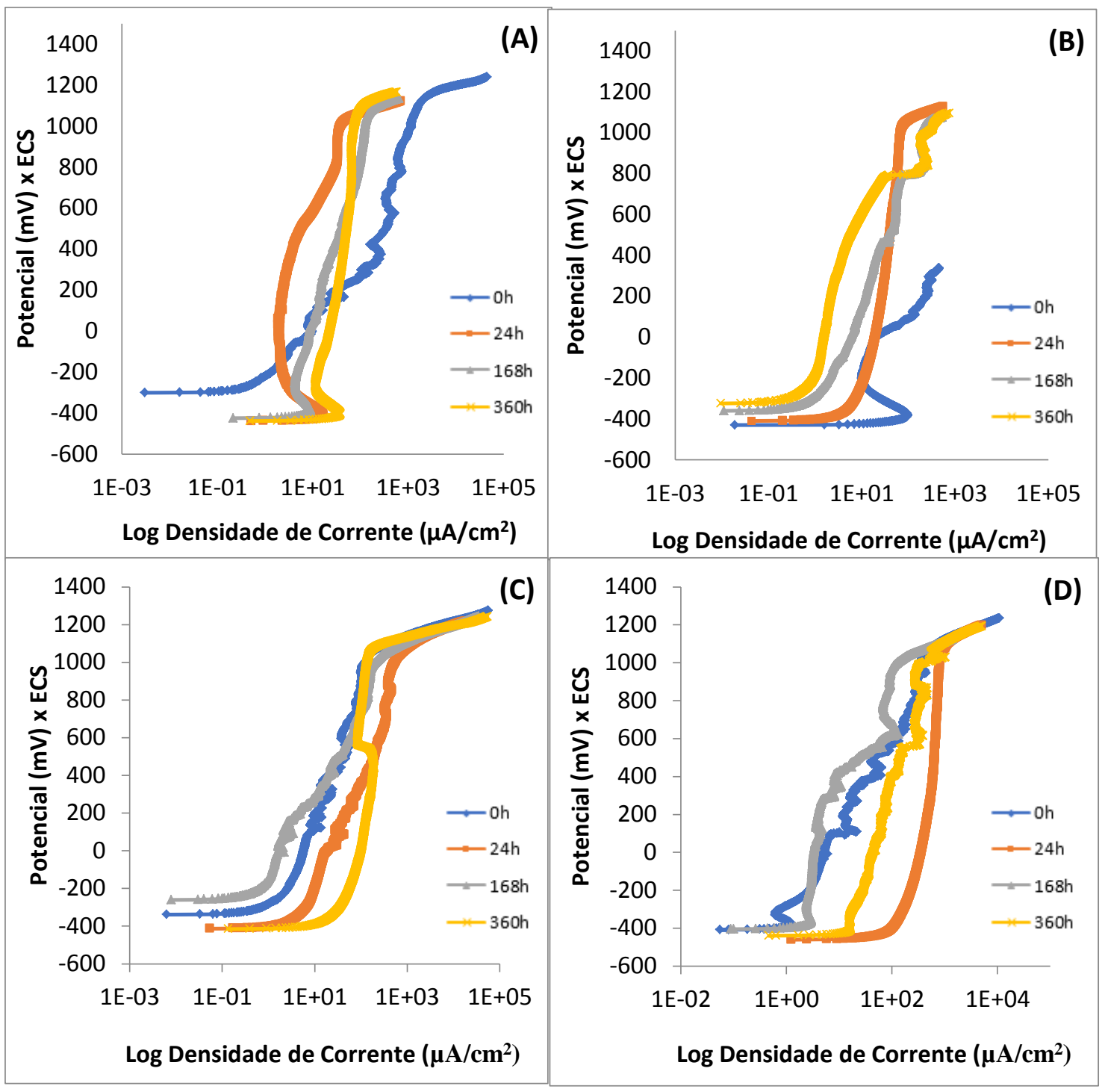

Figura 3: Curva de Polarização anódica para os ensaios conduzidos com Aço Duplex em água de produção na presença e ausência de microrganismos com aplicação de biocida na dose de 50 ppm (A-Branco 1 = sem biocida e sem microrganismos; B-Branco 2 = sem biocida e com microrganismos; C-Quat 1 = com biocida e sem microrganismos; D-Quat $2=$ com biocida e com microrganismos).

O sistema com microrganismos e sem biocida (Figura 3B) apresentaram curvas anódicas cujos potenciais de pite foram os mais baixos em comparação com o Branco 1 (Figura 3A). Apesar da diminuição sucessiva das densidades de corrente entre 0 hora e 360 horas, a manutenção das faixas passivas mostrou-se mais difícil com a elevação do potencial. Isso pode ser devido à característica dos microrganismos presentes, a ação de seus metabólitos normalmente ácidos e a um espessamento de um biofilme muito poroso nesta condição, que concomitantemente com íons agressivos facilitou o rompimento da camada passiva e ocasionou a diminuição do valor do potencial de pite.

As curvas de polarização anódicas com aplicação de Quats (Figura 3C), por sua vez, mostram perfis diferentes em comparação com os ensaios anteriores (Figura 3A e B). Nota-se que as curvas anódicas neste sistema tiveram comportamento parecidos, apesar de apresentarem oscilações nas densidades de corrente com o passar do tempo apresentando valores médios de densidade de corrente passiva em torno de 10 $\mu \mathrm{A} / \mathrm{cm}^{2}$, valor este que está dentro da faixa aceita para filmes de passivação. Neste ensaio, os potenciais de corrosão apresentam-se próximo dos valores observados de quando os microrganismos estavam ausentes (Figura $3 \mathrm{~A}$ ). Isso pode inferir a formação de um filme sobre a camada passiva de forma relativamente ho- 
mogênea, ainda que permita o contato do meio com a superfície metálica. Esses valores de potencial de pite mais próximos dos observados para o branco 1 (Figura $3 \mathrm{~A}$ ) podem sugerir que o Quat não funcionou como um "desestabilizador" da camada de passivação ao contrário do que foi visto quando os microrganismos estavam presentes face aos metabolitos por eles produzidos.

Na literatura não foi encontrado trabalhos onde analisou-se o comportamento de Quat na corrosão microbiológica do aço duplex UNS S 31803 principalmente contendo mais de um grupo bacteriano. No entanto, alguns trabalhos na literatura referenciam a capacidade inibitiva dos quaternários de amônio principalmente em meios ácidos, normalmente em valores de $\mathrm{pH}$ mais baixos do que 6 .

FUCHS-GODEC [31] estudaram o Quats na corrosão do aço carbono em ácido sulfúrico. Estes autores observaram que este composto químico apresentou boa eficiência na inibição da corrosão sendo que os resultados de polarização deste estudo revelaram que o Quats funciona como um inibidor de tipo misto.

HEGAZY et al. [32] avaliaram dois tipos de Quats como inibidores de corrosão sobre a corrosão do cobre em solução de $\mathrm{HNO}_{3} 1,0 \mathrm{~mol} \mathrm{~L}^{-1}$. Os resultados revelaram característica mista de inibição, com eficiências máximas de $93,9 \%$ e 90,8\%.

Em outro estudo, EL-DESOKY et al. [33] avaliaram o efeito de algumas formulações de Quats na inibição da corrosão de cobre em solução de $\mathrm{HNO}_{3} 2,0 \mathrm{~mol} \mathrm{~L}^{-1}$ e observaram que houve aumento da eficiência de inibição com o aumento da concentração do composto químico. Novamente, neste trabalho, os resultados de polarização mostraram que os Quats apresentaram característica mista de inibição, desacelerando ambos os processos anódicos e catódicos sobre a superfície do metal. Segundo estes autores, a capacidade da molécula adsorver a superfície depende do átomo principal de seu centro ativo.

Com relação às curvas anódicas na presença dos microrganismos (Figura 3D) observam-se oscilações maiores nas densidades de corrente de zona passiva ao longo dos diferentes tempos do experimento. Não houve diferenças significativas na extensão das faixas de passivação. No caso dos potenciais de pite, assim como na ausência de microrganismos (Figura 3A e C) apresentaram valores de potenciais de pite em torno de $1000 \mathrm{mV}_{\mathrm{ECS}}$.

Analisando comparativamente estes resultados com as análises de quantificação celular dos microrganismos (Figuras 1), observa-se que o biocida contendo Quats impactou todas os grupos bacterianos, inclusive eliminando alguns grupos antes presentes (BPAA e BRS). Os microrganismos que permaneceram provavelmente formaram um biofilme mais heterogêneo e disperso (diferente daquele formando quando não foi aplicado biocida) que provavelmente influenciou no comportamento das curvas anódicas. Isso demonstra que, embora o biocida tenha mantido os valores de potenciais de pites próximos do observado para o branco (Figura $3 \mathrm{~A}$ ) os microrganismos influenciaram no comportamento das curvas.

\section{CONCLUSÕES}

- Todos os grupos bacterianos promotores da corrosão microbiológica (BHA, BPAA, BPAAn e BRS) estavam presentes durante o período experimental quando o biocida (Quats) não foi aplicado no sistema. No entanto, com a aplicação do Quats, houve diminuição da quantidade celular dos grupos bacterianos, sendo que inclusive alguns grupos não foram detectados na fase planctônica (BRS) e séssil (BPAA e BRS).

- Os valores dos potenciais a circuito aberto no sistema onde o Quats foi aplicado permaneceram mais elevados, indicando a sua eficácia na corrosão microbiológica;

- No sistema onde o Quats foi aplicado, apesar de ter sido observado oscilações nas densidades de corrente do aço duplex, o potencial de pite manteve-se elevado (em torno de $1000 \mathrm{mVECS}$ ), mesmo na presença de microrganismos.

\section{AGRADECIMENTOS}

Os autores agradecem a Fundação de Amparo à Pesquisa e Desenvolvimento Científico do Maranhão (FAPEMA) pela concessão da bolsa de Professor-Pesquisador Visitante, à Fundação de Amparo à Pesquisa do Estado do Rio de Janeiro (FAPERJ), ao Laboratório de Corrosão "Professor Vicente Gentil" (EQ/UFRJ) e ao Laboratório de Biocorrosão (LABIO/INT) pelo apoio no desenvolvimento deste trabalho. 


\section{BIBLIOGRAFIA}

[1] GENTIL, V. Corrosão. Livros Técnicos e Científicos Editora S.A., 5 ed., Rio de Janeiro, 2011.

[2] VIDELA, H.A. Biocorrosão, biofouling e biodeterioração de materiais, 1a ed. São Paulo: Ed. Edgard Blucher Ltda, 2003.

[3] RAJASEKAR, A., GANESH BABU, T., KARUTHA PANDIAN, S., et al., "Biodegradation and corrosion behavior of manganese oxidizer Bacillus cereus ACE4 in diesel transporting pipeline", Corrosion Science. v.49, pp. 2694-2710, 2007.

[4] MADigAN, M. T., MARTINKO, J. M., DUNLAP, P.V., et al., Microbiologia de Brock . 12 ed. Porto Alegre, Artmed, 2010.

[5] LITTLE, B., LEE, J.S. Microbiologically influenced corrosion. USA, Wiley, 2007.

[6] EBRAHIMI, N., MOAYED, M.H., DAVOODI, A. "Critical pitting temperature dependence of 2205 duplex stainless steel on dichromate ion concentration in chloride médium", Corrosion Science. v.53 pp.12781287, 2011.

[7] GUO, L.Q., LIN, M.C., QIAO, L.J., et al., "Duplex stainless steel passive film electrical properties studied by in situ current sensing atomic force microscopy", Corrosion Science. v.78, pp.55-62, 2014.

[8] NASCIMENTO, A.M., IERARDI, M.C.F., KINA, A.Y., et al., "Pitting corrosion resistance of cast duplex stainless steels in 3.5\% NaCl solution”, Materials Characterizations, v.9, pp.1736-1740, 2008.

[9] LUTEY, R. W.. Process cooling water, In: Rossmore, H. W. ed. Handbookof Biocide and Preservative Use. Blackie Academic \& Professional, pp.51-82, Glasgow, UK, 1995.

[10] MAH, T. C., O’TOOLE, G. A. "Mechanisms of biofilm resistance to antimicrobial agents", Trends in Microbiology, v.9, n 1, pp. 34-39, 2001.

[11] POSTGATE, J. R. The sulphate-reducing bacteria. $2^{\mathrm{a}}$ ed. Press Sindicate of the University of Cambridge, New York, 1984.

[12] SOUSA, K.A. Avaliação da biogênese de sulfeto sob diferentes concentrações de bactérias redutoras de nitrato, bactérias redutoras de sulfato e nitrato, Tese de D. Sc., EQ/UFRJ, Rio de Janeiro, RJ, 2009.

[13] GAYLARDE, C. C. E., MORTON, L.H.G. "Deteriogenic biofilms on building and their control: a review", Biofouling, v.14, pp.59-74, 1999.

[14] ABELHO, M. Protocolo de Microbiologia Ambiental parte 3: Microbiologia Aplicada. Escola Superior de Agrária. Instituto Politécnico de Coimbra, 2013.

[15] TORTORA, G. J., FUNKE, B. R., CASE, C. L. Microbiologia. Atmed. 10 ed. Porto Alegre, 2012.

[16] CLOETE, T. E., JACOBS, L., BRÖZEL, V. S. "The chemical control of biofouling in industrial water systems", Biodegradation, n. 9, pp. 23-37, 1998.

[17] COSTERTON, J.W., LEWANDOWSKI, Z., CALDWELL, D.E., et al., "Microbial Biofilms", Annual Review of Microbiology, v. 49, pp.711-745, 1995.

[18] ALMEIDA, M. A. N., FRANÇA, F. P. "Biofilm formation on brass coupons exposed to a cooling system of an oil refinery", Journal of Industrial Microbiology, n. 20, pp. 39-44, 1998.

[19] SINDE, E., CARBALLO, J. "Attachment of Salmonella sp. And Listeria monocytogenes to stainless steel, rubber and polytetrafluorethylene: the influence of free energy and the effect of commercial sanitizers", Food Microbiology, v.17, n. 4, pp.439-447, 2000.

[20] MACHADO, I., GRAÇA, J., SOUSA, A. M., et al., "Effect of antimicrobial residues on early adhesion and biofilm formation by wild-type and benzalkonium chloride-adapted Pseudomonas aeruginosa", Biofouling, v.10, pp.1151-1159, 2011.

[21] PEREIRA, M. O., SIMÕES, M., MACHADO, S. M. D. O., et al., "Role of benzalkonium chloride surface preconditioning in the increased resistance of biofilms to removal and disinfection", In: International conference biofilm systems, Amsterdam, 2006.

[22] ChAVANT, P., GAILlARD-MARTINIE, B., HÉBRAUD, M. "Antimicrobil effects of sanitizers against planktonik and sessile Listeria monocytogenes cells according to the grownth phase", FEMS Microbiology Letters, Amsterdam, v.236, pp.241-248, 2004.

[23] ANDRADE, N.J., MACÊDO, J.A.B. Higienização na Industria de Alimentos. São Paulo, Varela, 1996. 
[24] DASCHNER, F. "The hospital and pollution role of the hospital epidemiologista in protecting the the environment", In: WENZEL, R. Prevention and controlo f nosocomial infections. 3.ed. Baltimore, Williams \& Wilkins, 1997.

[25] WOLYNEC, S. Técnicas Eletroquímicas em Corrosão. Editora USP, São Paulo, 2003.

[26] STAROSVETSKY, J., STAROSVETSKY, D., POKROY, B., et al., "Electrochemical behaviour of stainless steels in media containing iron-oxidizing bacteria (IOB) by corrosion process modeling", Corrosion Science, v.50, pp.540-547, 2008.

[27] ANTONY, P.J., RAMAN, R.K.S., MOHANRAM, R., et al., "Influence of termal aging on sulfatereducing bactéria (SRB)-influenced corrosion behaviour of 2205 duplex stainless steel", Corrosion Science, v.50 pp. 1858-1864, 2008.

[28] MORADI, M., SONG, Z., YANG, L., et al., "Effect of marine Pseudoalteromonas sp. on the microstructure and corrosion behavior of 2205 duplex stainless steel", Corrosion Science, v.84, pp.103-112, 2014.

[29] MALIK, M.A., HASHIM, M.A., NABI, F., et al., "Anti-corrosion ability of surfactants: A Review", Journal Electrochemical Science", v.6, pp.1927-1948, 2011.

[30] CAllaghan, D., BAUMGaRTNER, W., Proceedings SPE International Conference on Health, Safety, and Environment in Oil and Gas Exploration and Production, Houston, United States of America, 1990.

[31] FUCHS-GODEC, R. "The adsorption, CMC determination and corrosion inhibition of some $N$-alkyl quaternary ammonium salts on carbon steel surface in $2 \mathrm{M} \mathrm{H}_{2} \mathrm{SO}_{4}$ ", Colloids and Surfaces A: Physicochem. Eng. Aspects, v.280, pp.130-139, 2006.

[32] HEGAZY, M.A., NAZEER, A.A., SHALABI, K. "Electrochemical studies on the inhibition behavior of copper corrosion in pickling acid using quaternary ammonium salts", Journal of Molecular Liquids, v.209, p.419-427, 2015.

[33] EL-DESOKY, A.M., AHMED, H.M., ALI, A.E. "Electrochemical and Analytical Study of the Corrosion Inhibitory behavior of Expired Pharmaceutical Compounds for C- Steel Corrosion", International Journal of Electrochemical Science, v.10, pp. 5112-5129, 2015.

\section{ORCID}

Lindomar Cordeiro Antunes de Araújo

https://orcid.org/0000-0003-3309-5950

Paulo Roberto da Silva Ribeiro

https://orcid.org/0000-0001-5832-5623

Leila Yone Reznik

https://orcid.org/0000-0002-5786-979X

Márcia Teresa Soares Lutterbach

https://orcid.org/0000-0002-4906-4975

Eliana Flávia Camporese Sérvulo

https://orcid.org/0000-0001-5980-7587 